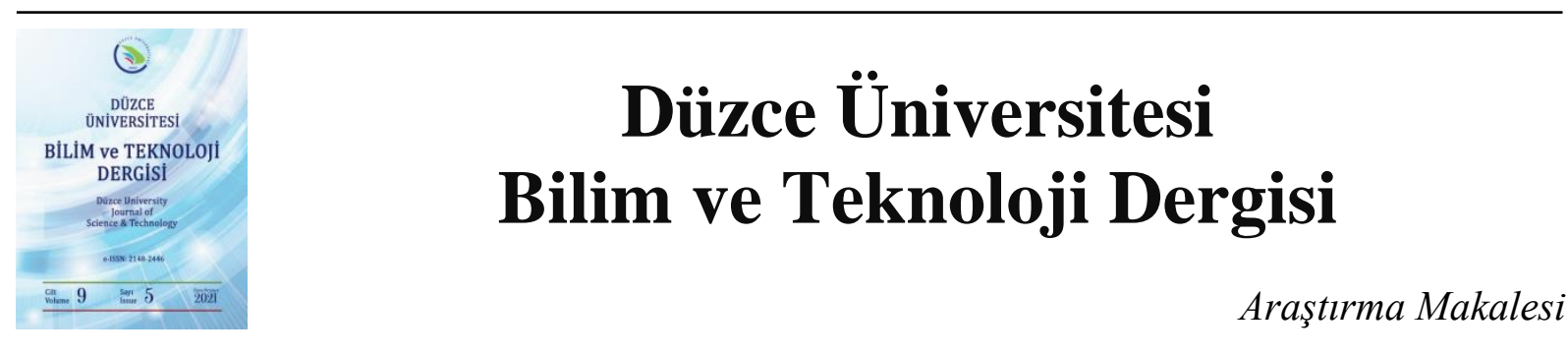

\section{Sıcak Presleme Yöntemiyle Üretilen Nb Takviyeli Mg Matrisli Kompozitlerin Mikroyapı ve Mekanik Özellikleri}

\author{
Ali ERÇETIN ${ }^{\mathrm{a}, *}$ \\ ${ }^{a}$ Makine Mühendisliği Bölümü, Mühendislik ve Mimarlık Fakültesi, Bingöl Üniversitesi, Bingöl, TÜRKIYYE \\ * Sorumlu yazarın e-posta adresi: aliercetin@bingol.edu.tr \\ DOI:10.29130/dubited.843535
}

\begin{abstract}
Öz
Toz metalurjisi (T/M) yöntemi, kompozit malzemelerin üretiminde en iyi yöntemlerden birisidir. Ancak, magnezyum $(\mathrm{Mg})$ tozlarının tutuşma riski sebebiyle $\mathrm{Mg}$ matrisli kompozitlerin bu yöntemle üretimi sınırlıdır. Bu çalışmada, $\mathrm{Mg}$ matrisli $\mathrm{Nb}$ partikül takviyeli kompozitlerin sıcak presleme yöntemiyle üretimi gerçekleştirilmiştir. Toz karışımlarının hazırlanması işleminden önce Mg tozlarının havayla temasını önlemek için parafin ile kaplama işlemi uygulanmıştır. Sinterleme işlemleri $630{ }^{\circ} \mathrm{C}$ sıcaklıkta, $50 \mathrm{MPa}$ basınç altında ve $90 \mathrm{dk}$ süreyle gerçekleştirilmiştir. Mikroyapı incelemeleri taramalı elektron mikroskobu (SEM), enerji dağılımlı spektroskopi (EDS) ve X-ışını kırınımı (XRD) analizleri ile, mekanik özellik incelemeleri ise sertlik testleri ile gerçekleştirilmiştir. Elde edilen sonuçlara göre, \%98'in üzerinde bağıl yoğunluk değerine sahip oldukça yoğun yapıda kompozitler elde edilmiştir. SEM görüntülerinde de gözenek oluşumuna rastlanmamıştır. XRD analizinde $\alpha-\mathrm{Mg}, \mathrm{Mg} 2 \mathrm{Sn}, \mathrm{MgZn}$ ve $\mathrm{Nb}$ fazlarına ait pikler oluşmuştur. Nb partikül takviyesi ile mekanik özelliklerde artış sağlanmıştır $\left(80,1 \mathrm{HV}_{(0,3)}\right.$ 'den 101,3 $\mathrm{HV}_{(0,3)}$ sertlik değerine kadar).
\end{abstract}

Anahtar Kelimeler:Mg matris, Kompozit, Nb takviyesi, Mikroyapı, Mekanik özellikler

\section{Microstructure and Mechanical Properties of $\mathrm{Nb}$ Reinforced Mg Matrix Composites Produced Through Hot Pressing Method}

\begin{abstract}
Powder metallurgy $(\mathrm{P} / \mathrm{M})$ method is one of the best methods in the production of composite materials. However, the production of $\mathrm{Mg}$ matrix composites by this method is limited due to the ignition risk of magnesium $(\mathrm{Mg})$ powders. In this study, the production of $\mathrm{Nb}$ particle reinforced $\mathrm{Mg}$ matrix composites was carried out by hot pressing method. Before the powder mixing preparations, a coating process with paraffin was applied to prevent the $\mathrm{Mg}$ powders from contacting with air. Sintering processes were carried out at $630{ }^{\circ} \mathrm{C}$ under $50 \mathrm{MPa}$ pressure and for 90 minutes. Microstructure investigations were carried out by scanning electron microscopy (SEM), energy dispersive spectroscopy (EDS) and x-ray diffraction (XRD) analyzes, and mechanical property examinations were performed by hardness tests. According to the results obtained, highly dense composites with relative density values over $98 \%$ were obtained. No pore formation was observed in SEM images. In XRD analysis, peaks of $\alpha-\mathrm{Mg}, \mathrm{Mg}_{2} \mathrm{Sn}, \mathrm{MgZn}$ and $\mathrm{Nb}$ phases were formed. Mechanical properties are increased with $\mathrm{Nb}$ particle reinforcement (from $80.1 \mathrm{HV}_{(0.3)}$ to $101.3 \mathrm{HV}_{(0.3)}$ hardness value).
\end{abstract}

Keywords: Mg matrix, Composite, $\mathrm{Nb}$ reinforcement, Microstructure, Mechanical properties 


\section{GIRIS}

Otomotiv ve havacılık sektörleri başta olmak üzere mobil iletişim cihazları, bilgisayarlar, laptoplar, askeri iletişim ekipmanları gibi uygulamalarda, taşıma esnasındaki enerji sarfiyatını minimum seviyeye indirebilmek için, en hafif yapısal metal olan $\mathrm{Mg}$ ve alaşımlarının kullanımına yönelik çalışmalar son yıllarda hız kesmeden devam etmektedir [1-4]. Mg ve alaşımlarının düşük yoğunluk, iyi işlenebilirlik, geri dönüştürülebilme ve titreşim sönümleme kabiliyeti gibi diğer özellikleri de tercih edilme sebepleri arasındadır [5-7].

$\mathrm{Mg}$ alaşımlarının mekanik özelliklerini geliştirmek için başta $\mathrm{Al}, \mathrm{Zn}, \mathrm{Mn}, \mathrm{Sn}, \mathrm{Si}$ olmak üzere farklı alaşım elementlerinin farklı oranlarda ilavesi gerçekleştirilmektedir [1,2,8-13]. Bu alaşımlar genellikle ikili veya üçlü alaşım sistemi olarak tasarlanmaktadır. İkili alaşım sistemlerinden bazıları AZ91, AZ31, AM60, AS21, ZK60, TZ54 magnezyum alaşımlarıdır $[1,8,10,12,14,15]$. Üçlü alaşım sistemlerine ise TAS831, TAZ811, TAZ1031, magnezyum alaşımları örnek olarak gösterilebilir [1618]. Ancak, $\mathrm{Mg}$ alaşımlarının oda sıcaklığında hegzagonal sıkı paket kristal yapısında olması nedeniyle süneklik ve şekillendirilebilirlik özellikleri düşüktür [11,19-21]. Dolayısıyla, bu sıcaklıkta zorlamaya maruz kaldığında mikroyapıda çatlama meydana gelmesi muhtemeldir [22,23]. $\mathrm{Mg}$ alaşımına takviye elemanı ilavesiyle kompozit oluşturulması sayesinde çatlama ve plastik deformasyona karşı dayanımın iyileştirildiğine dair bilimsel çalışmalar gerçekleştirilmiş ve halen yeni Mg matrisli kompozitler üzerine çalışmalar devam etmektedir [24-27].

$\mathrm{Mg}$ alaşımlarına SiC [24], TiC [26], CNT [27], CNT/SiC [28] ve $\mathrm{Al}_{2} \mathrm{O}_{3}$ [29] ilavelerinin mikroyapı ve mekanik özelliklere etkisine dair literatürde birçok çalışma olduğu görülmektedir. $\mathrm{Mg}$ alaşım matrisli kompozitlerin üretiminde genellikle karıştırmalı döküm ve basınçlı döküm yöntemlerinin kullanılmaktadır. Partikül takviyeli kompozitlerin üretiminde homojen bir karışım ve homojen bir mikroyapı elde edilmesinde toz metalürjisi yöntemi daha yüksek başarıya sahiptir [28,30-33]. Ancak geleneksel toz metalurjisi yöntemiyle üretimde de döküm yönteminde olduğu gibi imalat işlemi sonrasında numunelerde tam yoğunlaşma gerçekleşememekte ve belirli bir sicaklık üzerinde ekstrüzyon ilave prosesine ihtiyaç duyulmaktadır [10]. Ancak, $\mathrm{Mg}$ matrisli kompozitlerin üretimi toz metalurjisi yöntemlerinden sıcak presleme ile üretilirse, hem homojen mikroyapı oluşumu sağlanabilecek hem de presleme ve sinterleme eş zamanlı uygulandığı için yüksek bağıl yoğunluklu kompozitler elde edilebilecektir [12,34]. Üretim esnasında $\mathrm{Mg}$ alaşım matrisli kompozitlerin oksidasyona maruz kalmaması için $\mathrm{Mg}$ tozlarına karışım öncesi koruyucu bir kaplama tekniği uygulanması başarıyı arttıracaktır [10,34].

Literatür çalışmaları incelendiğinde, $\mathrm{Mg}$ alaşımı matrisine $\mathrm{Nb}$ takviyesi ile ilgili çok az sayıda çalışma bulunmaktadır.Nb takviyeli Mg matrisli kompozitler üzerine yeni bulguların literatüre kazandırılması gerekmektedir. $\mathrm{Bu}$ nedenle, bu çalışmada, $\mathrm{Mg}$ alaşımı matrisine mikron boyutlarında $\mathrm{Nb}$ partikül takviyesinin mikroyapı ve mekanik özelliklere etkisi incelenmiştir. Mekanik özelliklere etkisi açısından optimum ilave oranları belirlenen $\mathrm{Sn}$ ve $\mathrm{Zn}$ alaşım elementleri sabit oranlarda karışımda yer edinmiştir. Matris alaşımı için karışımlarda ağırlıkça \%5 Sn ve \%4 Zn kullanılmıştır. Nb içerisinde ağırlıkça \%7,4 oranına kadar Al alaşım elementi çözünebilmektedir [35]. Bu nedenle, içeriğinde Al içermeyen $\mathrm{Mg}-\mathrm{Sn}-\mathrm{Zn}$ alaşımı matris olarak seçilmiştir. Sıcak presleme yöntemiyle üretilen $\mathrm{Nb}$ takviyeli numunelerin mikroyapı incelemeleri ve sertlik testleri gerçekleştirilmiştir.

\section{MALZEME VE YÖNTEM}

\section{A. KIMMYASAL BİLEŞIMLER}

Çalışmada $\mathrm{Mg}, \mathrm{Zn}, \mathrm{Sn}, \mathrm{Nb}$ tozları kullanılarak TZ54 alaşımı matrisli, farklı oranlarda $\mathrm{Nb}$ takviyeli kompozitler üretilmiştir. TZ54 matris alaşımına ait kimyasal bileşenler Tablo 1'de, Nb takviyeli kompozitlere ait kimyasal bileşenler ise Tablo 2'de verilmiştir. 
Tablo 1. TZ54 alaşımı matrisine ait ağırlıkça \% kimyasal bileşenler

\begin{tabular}{|c|c|c|c|}
\hline Matris & $\begin{array}{c}<45 \mu \text { m partikül } \\
\text { boyutu; } \\
\% 99,8 \text { saflık }\end{array}$ & $\begin{array}{c}<10 \mu \text { m partikül } \\
\text { boyutu; } \\
\% 99,9 \text { saflık }\end{array}$ & $\begin{array}{c}<10 \mu m \text { partikül } \\
\text { boyutu; } \\
\% 99,9 \text { saflık }\end{array}$ \\
\hline Kodu & $\begin{array}{l}\mathbf{M g} \\
(\%)\end{array}$ & $\begin{array}{c}\text { Sn } \\
(\%)\end{array}$ & $\begin{array}{l}\mathbf{Z n} \\
(\%)\end{array}$ \\
\hline TZ54 & 91 & 5 & 4 \\
\hline
\end{tabular}

Tablo 2. TZ54-xNb kompozit numunelerine ait ağırlıkça \% kimyasal bileşenler

\begin{tabular}{ccc}
\hline \multirow{2}{*}{$\begin{array}{c}\text { Kompozit } \\
\text { Kodu }\end{array}$} & $\begin{array}{c}<\boldsymbol{\mu} \text { mpartikül } \\
\text { boyutu; } \\
\mathbf{\% 9 9 , 8 ~ s a f l ı k}\end{array}$ \\
\cline { 2 - 3 } & $\begin{array}{c}\text { TZ54 } \\
(\%)\end{array}$ & $\begin{array}{c}\text { Nb } \\
(\%)\end{array}$ \\
\hline TZ54 +\%3 Nb & 97 & 3 \\
TZ54 +\%6 Nb & 94 & 6 \\
TZ54 +\%9 Nb & 91 & 9 \\
TZ54 +\%12 Nb & 88 & 12 \\
\hline
\end{tabular}

\section{B. KARIŞIMLARIN HAZIRLANMASI}

Çalışmada, yukarıdabelirtilen oranlarda tozlar karıştırılmadan önce $\mathrm{Mg}$ tozlarına parafin kaplama tekniği uygulanmıştır [10]. Mg tozları 500 gr'lık vakumlu paket içerisinde temin edilmiş ve parafin kaplama işleminde tamamı kullanılmıştır. Paketin eldivenli kabin (glove box) içerisinde açılmasından önce, kabin yüksek saflıkta argon gazı ile doldurulmuş, daha sonra vakuma alınmıştır. Eldivenli kabinde paketin açılmasıyla Mg tozlarının tamamı, içerisinde $250 \mathrm{~mL}$ hekzan bulunan $1000 \mathrm{~mL}$ 'lik behere boşaltılmıştır. Paketin dolu ve boş ağılıkları farkı alınarak, Mg tozlarının net ağırlığı tespit edilmiştir. $\mathrm{Mg}$ tozunun hacmi, ağırlık/yoğunluk oranına göre hesaplanmış ve hacimce $\% 20$ oranında olacak şekilde \%99,9 saflığa sahip parafin cam beher içerisine ilave edilmiştir. Hegzanın parafini çözmesi için beher içerisindeki karışım hassas bir 1sıtıcıda $70{ }^{\circ} \mathrm{C}$ 'ye kadar 1sıtılmıştır. Tozların topaklanmadan homojen karışımı için beher içerisindeki karışıma, pervaneli bir karıştırıcı daldırılmıştır. Karışım 180 dev/dk hızında 1 saat süreyle karıştırılmıştır. Hekzan karışım içerisinden tamamen buharlaştırılarak Mg tozlarının parafin ile kaplanması sağlanmıştır. Matris alaşımı ve kompozisyon bileşenlerine ait karışımların tartımı ve hazırlanması işleminde hacimce parafin oranı hesaplamalarda dikkate alınmış ve aynı karıştırma teknikleri uygulanmıştır. Tozların ve karışımların tartım işlemlerinde $10^{-4}$ grhassasiyetine sahip Precisia marka hassas terazi kullanılmıştır.

\section{KOMPOZITNUMUNELERIN ÜRETIMI VE METALOGRAFÍK HAZIRLIKLAR}

Hazırlanan karışımlar grafit kalıplar içerisine yerleştirilerek sıcaklık ve basıncın eş zamanlı uygulandığı sıcak pres cihazına yerleştirilmiştir. Sinterleme işlemi $630{ }^{\circ} \mathrm{C}$ sıcaklıkta $50 \mathrm{MPa}$ basınç altında ve argon gaz atmosferinde $90 \mathrm{dk}$ süreyle gerçekleştirilmiştir. Farklı $\mathrm{Nb}$ partikül takviyesi içeren numuneler 30x10x3 mm boyutlarında üretilmiştir. Sinterlenen numuneler sırasiyla 240, 400, 600, 800, 1000, 1200 ve 1500 numaralı zımpara kâğıtlarıyla zımparalama işlemine tabi tutulmuştur. Son zımparalama işleminden sonra 1 mikronluk elmas süspansiyon kullanılarak numuneler parlatılmıştır. Dağlama işleminde hacimce \%95 etil alkol ve \%5 nitrik asit kullanılmıştır. Dağlama işlemi sonrasında numuneler saf su ve etil alkol ile temizlenmiş ve kurulanmıştır. 


\section{UYGULANAN ANALIZLER VE TESTLER}

Numunelerin yüzey mikroyapı incelemelerinde taramalı elektron mikroskobu (SEM) ve enerji dağılımlı spektroskopi (EDS) analizleri, mikroyapıda oluşan fazların tayininde x-1şını kırınımı (XRD) analizi uygulanmıştır. Numunelerin bağıl yoğunlukları, ölçülen/teorik yoğunluk oranına göre belirlenmiştir. Ölçülen yoğunluk değerleri Arşimed prensibine göre tespit edilmiştir [34].

Sertlik ölçümleri Labtt marka mikro Vickers sertlik cihazında 300 gr yük 10 sn süre uygulanarak gerçekleştirilmiştir. Her bir numunenin 7 farklı bölgesinden alınan sertlik değerlerinin ortalaması ilgili numunenin sertlik değeri olarak kabul edilmiştir.

\section{BULGULAR VE TARTISYMA}

\section{A. YOĞUNLUK VE BAĞIL YOĞUNLUK VERILERINIIN DEĞERLENDİRILMESİ}

Farklı oranlarda $\mathrm{Nb}$ partikül takviyesi içeren TZ54 alaşımı matrisli kompozitlere ait teorik ve ölçülen yoğunluk ile \% bağıl yoğunluk sonuçları Şekil 1'de verilmektedir. Ölçülen yoğunluk değerleri, teorik yoğunluk değerlerine oldukça yakındır. Artan $\mathrm{Nb}$ partikül takviyesi ile birlikte her iki yoğunluk sonucu da artış göstermektedir. Nb takviyesindeki artışla, \% bağıl yoğunluk değerlerinin azaldığını söylemek mümkündür. Ancak, en düşük \% bağıl yoğunluk değerinin dahi \%98,06'nın üzerinde elde edilmesi, her bir numuneye ait sinterleme işlemlerinin başarıyla gerçekleştiğine işaret etmektedir. Matris alaşımı ve ağırlıça $\% 3, \% 6, \% 9$ ve $\% 12 \mathrm{Nb}$ içeren numunelerin teorik yoğunlukları sırasıyla $1,867,1,912,1,959,2,009$ ve $2,061 \mathrm{gr} / \mathrm{cm}^{3}$ iken, ölçülen yoğunluk değerleri ise sirasiyla $1,853,1,889$, $1,930,1,972$ ve $2,021 \mathrm{gr} / \mathrm{cm}^{3}$ olarak tespit edilmiştir.

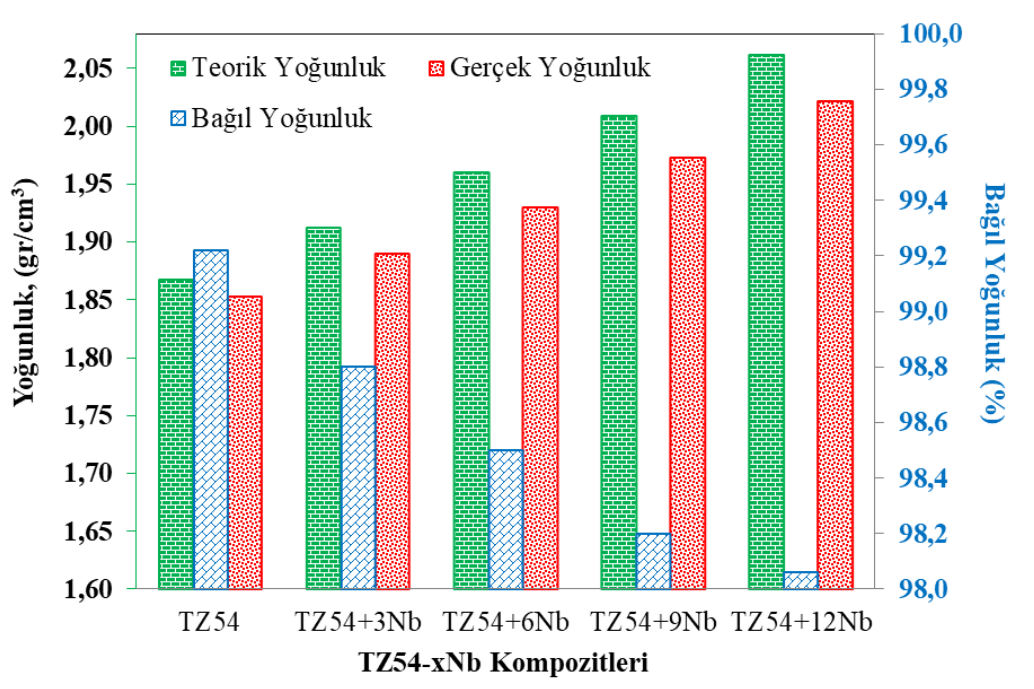

Şekil 1. Kompozit numunelere ait yoğunluk ve bağıl yoğunluk değerleri.

\section{B. KOMPOZIT NUMUNELERIN XRD ANALIZZLERI}

Şekil 2'deki grafik TZ54-xNb kompozit numunelerine ait XRD desenlerini göstermektedir. $\alpha-\mathrm{Mg}$ birincil fazı ile $\mathrm{Mg}_{2} \mathrm{Sn}$ ve $\mathrm{MgZn}$ intermetalik ikincil fazlarına ait pikler, tüm kompozit numunelerin XRD desenlerinde görülmektedir. Takviye olarak ilave edilen $\mathrm{Nb}$, matris $\mathrm{Mg}$ veya ilave edilen alaşım elementlerinden $\mathrm{Sn}$ ve $\mathrm{Zn}$ ile beraber herhangi bir faz oluşturmadığından XRD desenlerinde $\mathrm{Nb}$ fazı olarak pik vermiştir. Bu faza ait pik sadece $\mathrm{Nb}$ partikül takviyesinin yapıldı̆̆ 1 numunelerde elde edilmiştir. Artan Nb takviye oranına bağlı olarak XRD desenlerindeki Nb pik şiddetlerinin de arttı̆̆ını söylemek mümkündür.Shanthi ve arkadaşları [36], Mg'ye farklı oranlarda $\mathrm{Nb}$ takviyesi yaptıklarında XRD analizinde sadece $\alpha-\mathrm{Mg}$ ve $\mathrm{Nb}$ fazlarına ait pikler elde etmişlerdir. Bu çalışmadaki sonuçlara 
benzer bir şekilde artan $\mathrm{Nb}$ takviye oranına bağlı olarak $\mathrm{Nb}$ fazına ait pik şiddetlerinin arttığını tespit etmişlerdir. Herhangi bir numuneye ait XRD deseninde oksit içerikli bir faz bulunmaması iki sonucu ortaya çıkarmaktadır. Birincisi, parafin kaplama tekniği ile tozların karıştırma işleminden sinterlenmesi aşamasına kadar havayla temasının önlenebilmiş olmasıdır. İkincisi ise, sinterleme esnasında numunelerin oksidasyona maruz bırakılmadan başarıyla üretilebilmesidir.

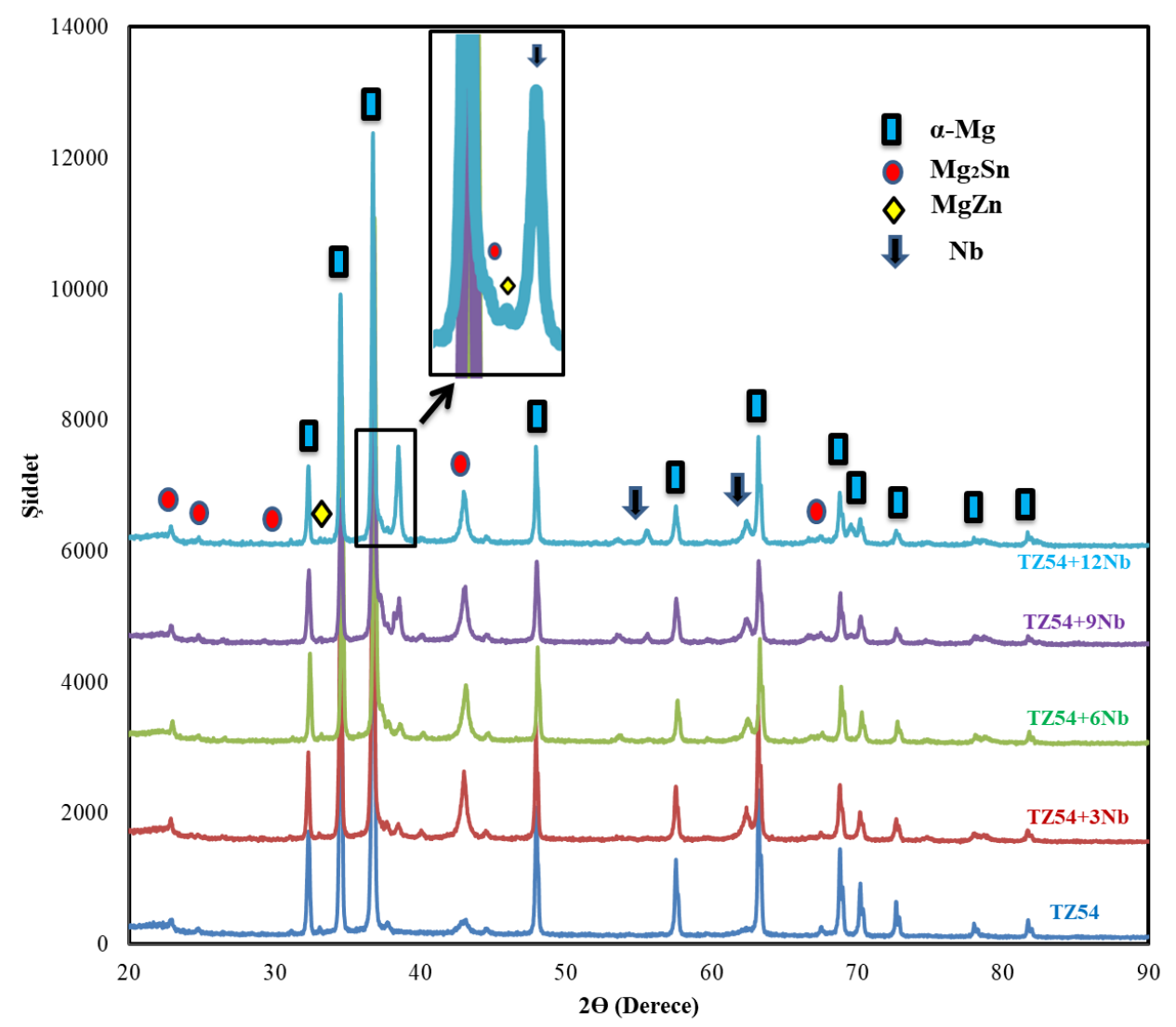

Şekil 2. TZ54-xNb kompozit numunelerine ait XRD desenleri

\section{SEM/EDS ANALIZLERI}

Şekil 3’te, $\% 9 \mathrm{Nb}$ takviyesi içeren kompozit numunesine ait SEM görüntüsü ve mikroyapıda farklı bölgelerden alınan noktasal ve alansal EDS sonuçları verilmektedir. EDS sonuçlarına göre işaretli yerler ile XRD analizinde tespit edilen fazlar oldukça benzerlik göstermektedir. Tane sınırı üzerindeki beyaz renkli ince ve küçük yapılar 1 nolu kırmızı oklar ile gösterilmiştir. 1 nolu yapıya ait noktasal EDS sonucuna göre $\mathrm{Mg}$ ve $\mathrm{Sn}$ içeriklerinin yüksek oranda olduğu görülmektedir. Dolayısıyla bu yapı XRD analizinde tespit edilen $\mathrm{Mg}_{2} \mathrm{Sn}$ intermetalik fazına ait olduğu görülmektedir. 2 nolu sarı ok ile gösterilen yapıda $\mathrm{Nb}$ miktarı oldukça fazladır. Dolayısıyla, sarı ok ile gösterilen yapıların $\mathrm{Nb}$ takviye elemanına ait olması gerekmektedir. Nb fazına ait yapıların sadece tane sınırlarında olduğu ve diğer yapılara göre daha iri boyutlarda olduğu net bir şekilde görülmektedir. Matris üzerinden alınan 3 nolu EDS alan analizine göre, yüksek oranda $\mathrm{Mg}$ içeriği ile birlikte az miktarda da olsa $\mathrm{Sn}$ ve $\mathrm{Zn}$ içerikleri de tespit edilmiştir. Bu durumun nedeni, oda sıcaklığında $\mathrm{Sn}$ ve $\mathrm{Zn}$ 'nin $\mathrm{Mg}$ içerisinde düşük oranda da olsa çözünürlüklerinin olmasıdır. Benzer bir çalışmada [10], oda sıcaklığında Zn'nin Mg içerisinde \%2 civarında çözünebildiği ve Sn'nin bu orandan daha az çözünebildiğinden bahsedilmiştir. Mg-Zn ve Mg-Sn ikili faz diyagramları incelendiğinde de aynı kanıya ulaşılacaktır. Tane sınırı üzerinden alınan 4 nolu alansal EDS sonucuna göre, ilave edilen her bir element içeriği kayda değer oranda bulunmaktadır. Zn ve Sn içerikleri, tane içlerine kıyasla tane sınırlarında daha yüksek oranlarda tespit edilmiş̧tir. $\mathrm{Bu}$ durum, numunelerin oda sıcaklığına kadar soğutulması esnasında, $\mathrm{Zn}$ ve Sn'nin tane içlerinden tahliye olurken tane sınırlarında $\mathrm{Mg}_{2} \mathrm{Sn}$ ve $\mathrm{MgZn}$ intermetalik fazlarını oluşturmasıyla açıklanabilir. 


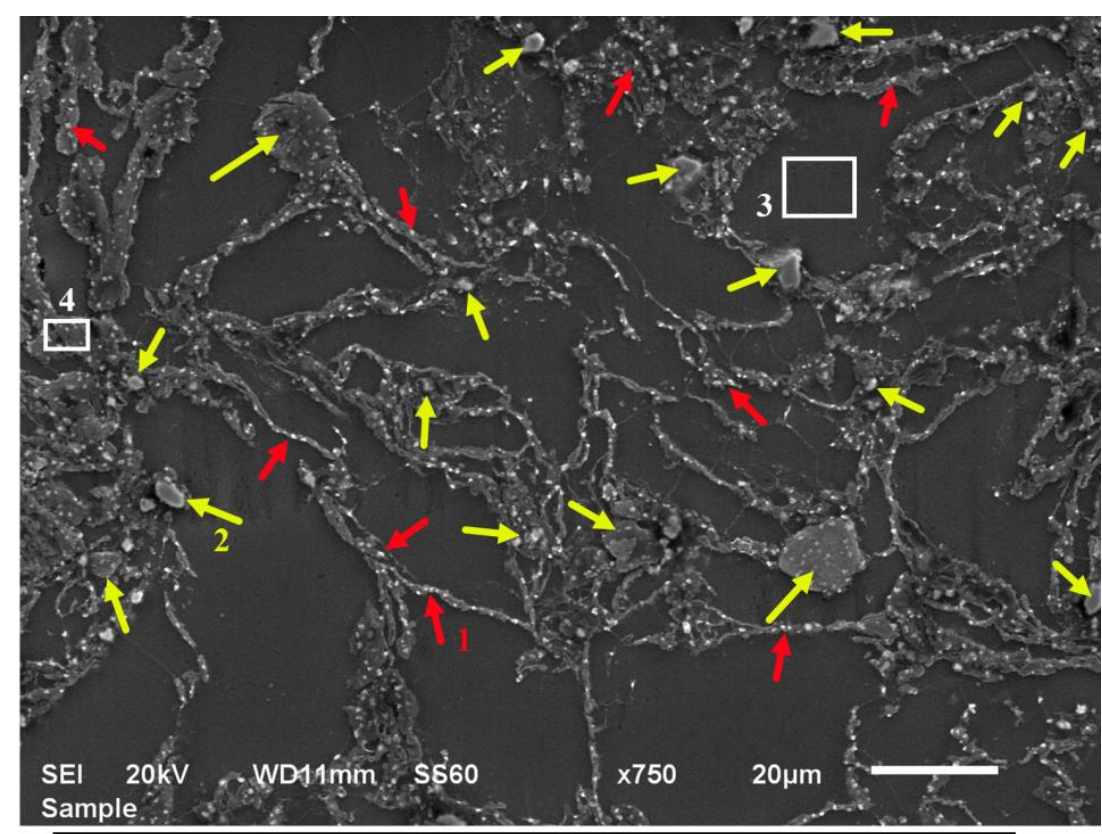

\begin{tabular}{ccccc}
\hline Nokta ve Alan Analizler & $\left(\begin{array}{c}\mathbf{\%}) \mathbf{M g} \\
\mathbf{1}\end{array}\right.$ & $\mathbf{( \% )} \mathbf{S n}$ & $\mathbf{( \% )} \mathbf{Z n}$ & $\mathbf{( \% )} \mathbf{~ N b}$ \\
2 & 61,56 & 38,44 & - & - \\
3 & 1,11 & 0,09 & 0,04 & 98,76 \\
4 & 98,51 & 0,21 & 1,28 & - \\
& 38,96 & 22,54 & 10,36 & 28,14 \\
\hline
\end{tabular}

Şekil 3. \%9 Nb takviyesi içeren kompozit numunesine ait SEM görüntüsü ve mikroyapıda farklı bölgelerden alınan noktasal ve alansal EDS sonuçları

TZ54-xNb kompozit numunelerine ait SEM görüntüleri Şekil 4'te görülmektedir. SEM görüntüleri incelendiğinde ilk dikkat çeken durum, artan $\mathrm{Nb}$ takviyesiyle birlikte tane sınırlarında $\mathrm{Nb}$ fazına ait yapıların yoğunluğunun da arttığıdır. Bütün kompozit numunelere ait yüzeyden alınan mikroyapı görüntülerinde intermetalik ikincil fazlar tane sınırlarında homojen bir şekilde dağılmıştır. Takviye oranındaki artışla birlikte aynı zamanda mikroyapıdaki tane boyutlarında da küçülmeler söz konusudur. Bununla birlikte, mikroyapı görüntülerinin gözenek içermemesi Şekil 1'deki yoğunluk ölçüm sonuçlarını da destekler niteliktedir. Takviye elemanı ile matrisin temas sınırlarında da özellikle gözenek olmaması, takviye ile matris arasında iyi bir ıslanabilirlik sağlandığını da göstermektedir.

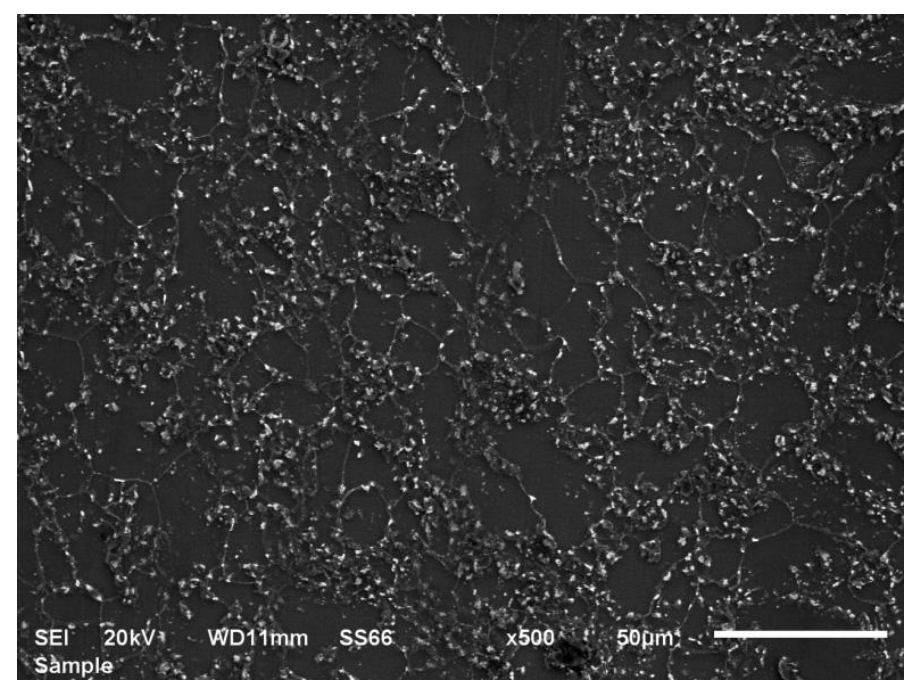

(a) 


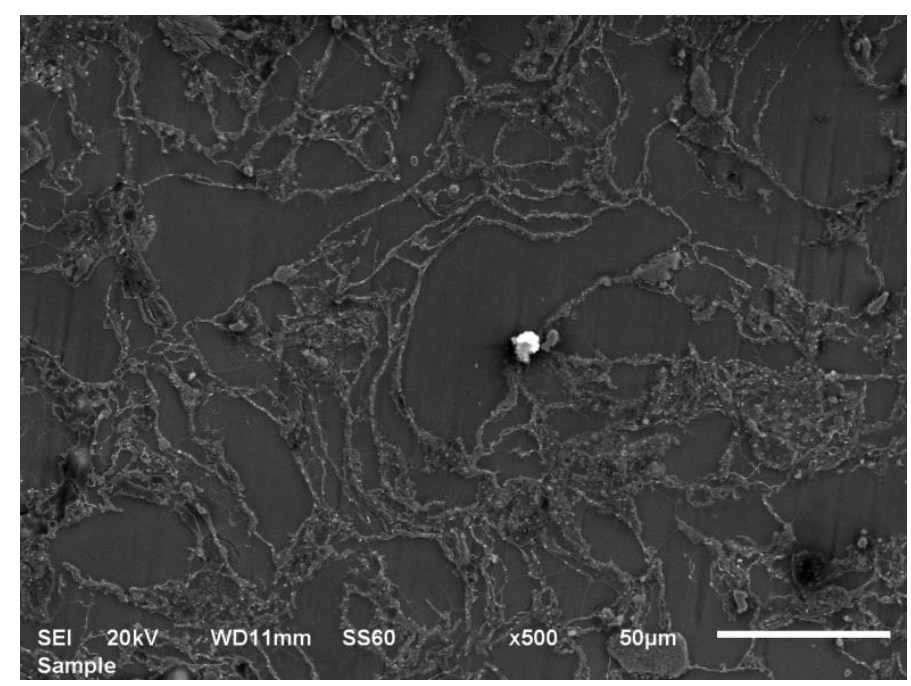

(b)

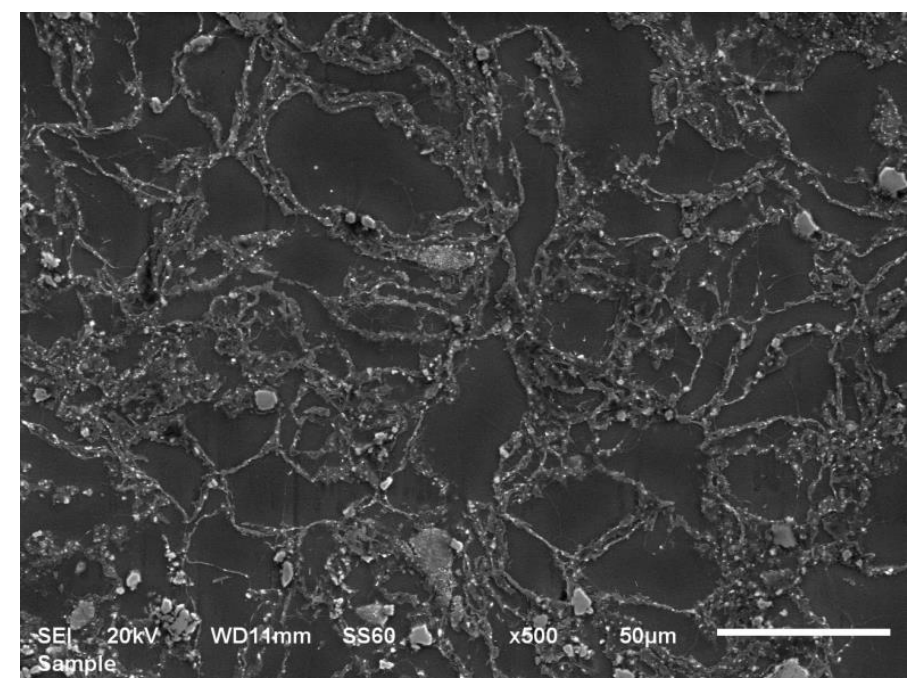

(c)

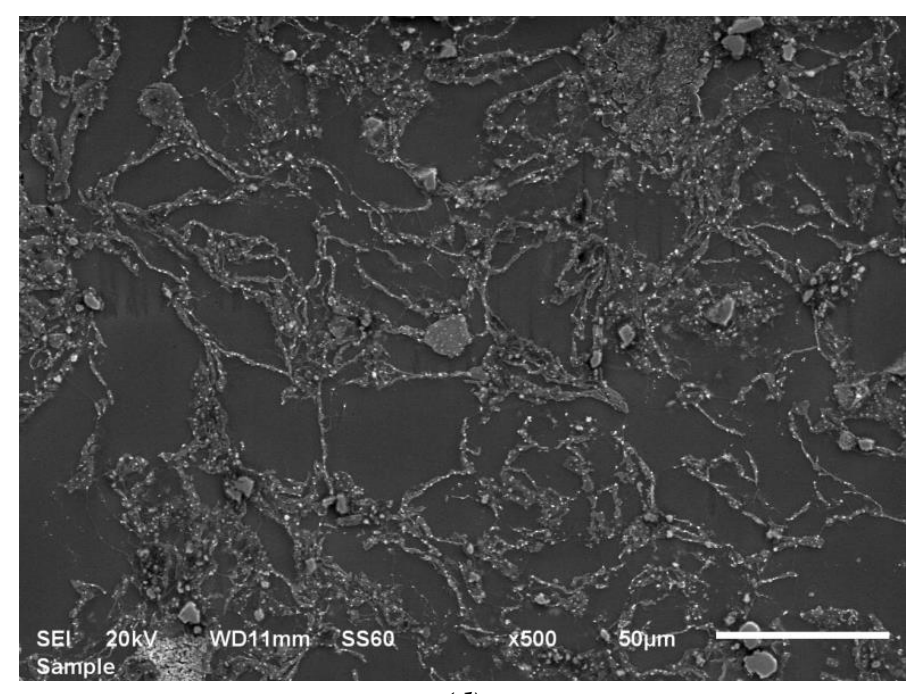

(d) 


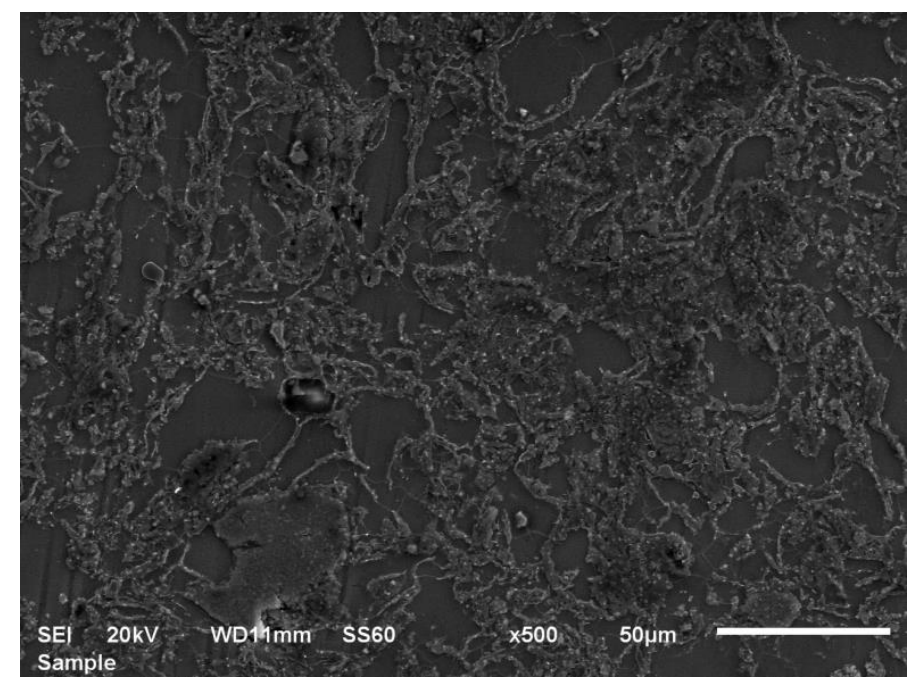

(e)

Şekil 4. TZ54-xNb kompozit numunelerine ait SEM görüntüleri; (a) TZ54 matrisi, (b) \%3 Nb takviyeli, (c) \%6 $\mathrm{Nb}$ takviyeli, (d) $\% 9 \mathrm{Nb}$ takviyeli, (e) \%12 $\mathrm{Nb}$ takviyeli

\section{SERTLIK SONUÇLARININ DEĞERLENDIRILMESİ}

Farklı oranlarda $\mathrm{Nb}$ partikül takviyesi içeren kompozit numunelere ait mikro sertlik ve ölçülen yoğunluk değerleri Şekil 5'te verilmiştir. Matris alaşımı ve ağırlıça \%3, \%6, \%9 ve \%12 Nb oranında takviye içeren kompozit numunelerin ortalama sertlik değerleri sırasıyla 80,1, 87,7, 89,8, 95,4 ve 101,3 HV $(0,3)$ olarak elde edilmiştir. En düşük ortalama sertlik değeri, matris alaşımı olan TZ54 magnezyum alaşımından elde edilirken, en yüksek sertlik değeri ise, ağırlıkça \%12 $\mathrm{Nb}$ takviyesi içeren kompozit numunesinden elde edilmiştir. Artan $\mathrm{Nb}$ ilavesinin sertlik özelliklerini geliştirdiğini söylemek mümkündür. Numunelerin sahip olduğu yoğunluk değerlerinin $\mathrm{Nb}$ takviye oranına bağl1 olarak artışı, sertlik özelliklerini pozitif etkilediği de görülmektedir. Shanthi ve arkadaşlarının saf Mg'ye $\mathrm{Nb}$ ilavesi üzerine bir çalışmada [36], artan takviye oranı kompozit numunelerin sertlik özelliklerini genel olarak arttırmış ve en yüksek sertlik değeri Mg-\%10Nb numunesinden $51 \mathrm{HV}$ olarak elde edilmiştir. AZ91 magnezyum alaşımına zirkonya $(\mathrm{ZrO} 2)$ ilavesinin yapıldığ ${ }_{1}$ bir başka çalışmada ise[37], ağırlıç̧a $\% 3, \% 6, \% 9$ ve $\% 12$ oranlarında zirkonya ilavesi yapılmış ve artan takviye oranına bağlı olarak sertlik değerleri sürekli artış göstermiştir. En yüksek sertlik değeri, ağırlıkça \%12 zirkonya takviyesini içeren kompozit malzemesinden $67,8 \mathrm{HB}$ olarak elde edilmiştir. Bu değer yaklaşı olarak $71 \mathrm{HV}$ değerine tekabül etmektedir. Şimdiki çalışmada üretilen TZ54-\%12Nb kompozit numunesinin sertlik değeri, Mg-\%10Nb kompozit numunesinden \%98, AZ91-\%12ZrO2 kompozitinden yaklaşı $\% 42$ daha fazladır. 


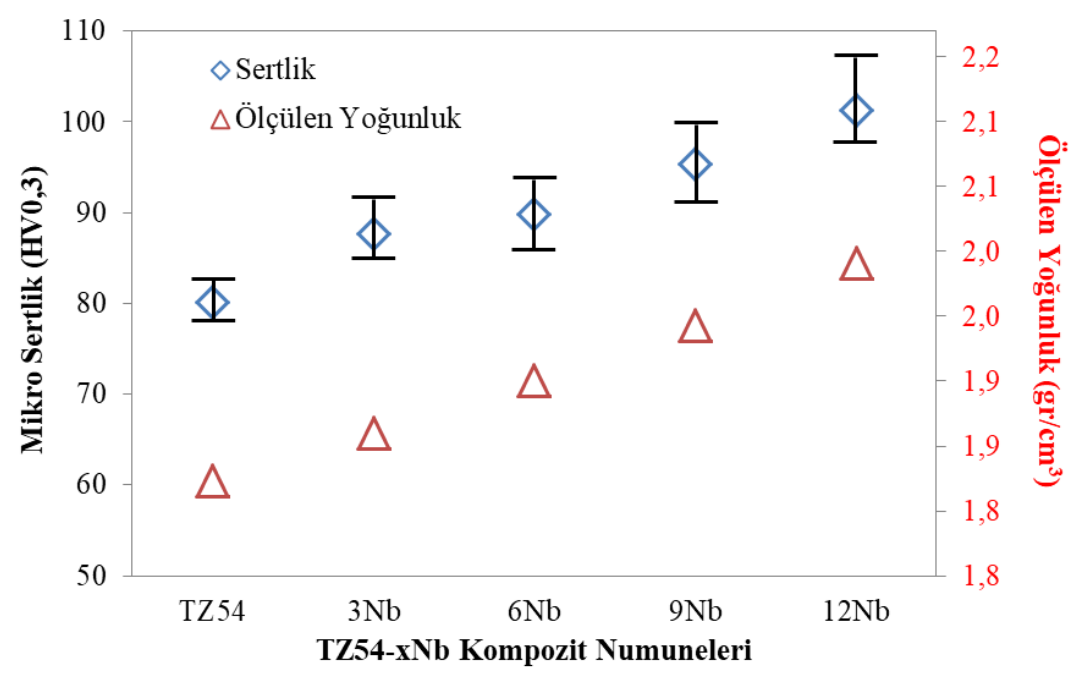

Şekil 5. TZ54-xNb kompozit numunelerine ait mikro sertlik ve ölçülen yoğunluk değerleri

\section{IV.SONUCLAR}

$\mathrm{Nb}$ partikül takviyeli Mg matrisli kompozitlerin sıcak presleme yöntemiyle üretimi başarılı bir şekilde gerçekleştirilmiştir. Ekstrüzyon gibi herhangi bir ilave parça yoğunlaştırma işlemine gerek duymadan, tek seferde oldukça düşük gözenek oranına ve yüksek bağıl yoğunluğa sahip kompozit parçalar, sıcak presleme yöntemi ile üretilebilmiştir. Bununla birlikte, sinterleme öncesinde Mg tozlarının parafin ile kaplanması bütün numunelerin üretiminde oksidasyon oluşumunu engellemiştir.

Numunelere ait mikroyapılarda, tane içlerinde $\alpha-\mathrm{Mg}$ fazı, tane sınırlarında ise $\mathrm{Mg}_{2} \mathrm{Sn}, \mathrm{MgZn}$ ve $\mathrm{Nb}$ fazları XRD ve EDS analizlerinin karşılaştırmalı incelenmesi sonucu belirlenmiştir. Mikroyapıda varlığı tespit edilen fazlar homojen bir dağılım sergilemiştir.

Artan $\mathrm{Nb}$ partikül takviye oranıyla birlikte ölçülen yoğunluk değerlerinde artış gerçekleşirken, kompozit numunelerin sertlik özelliklerinde de ciddi oranda gelişme sağlanmıştır( $80,1 \mathrm{HV}_{(0,3)}$ ' den $101,3 \mathrm{HV}_{(0,3)}$ sertlik değerine kadar). En yüksek sertlik değeri $\left(101,3 \mathrm{HV}_{(0,3)}\right) \% 12 \mathrm{Nb}$ içeren kompozit numunesinden elde edilmiştir.

TEȘEKKÜR: XRD ve SEM analizlerinin gerçekleştirilmesinde verdikleri emeklerden dolayı Bingöl Üniversitesi Merkez Laboratuvarı'na, Makine Mühendisliği Bölümü’ne sağladığı cihaz desteğinden dolayı Bingöl Üniversitesi'ne teşekkürlerimi sunarım.

\section{KAYNAKLAR}

[1] B. Akyüz, "AZ21 ve AJ21 Magnezyum alaşımlarının mekanik özellikleri ve işlenebilirliği," Düzce Üniversitesi Bilim ve Teknoloji Dergisi, c. 7, s. 3, ss. 1019-1028, 2019.

[2] B. Akyüz, "AZ91, AS91 ve AM90 Magnezyum alaşımlarının aşınma ve ısıl davranışları üzerine karşılaş̧ırmalı bir çalışma," Bilecik Şeyh Edebali Üniversitesi Fen Bilimleri Dergisi, c. 7, s. 2, ss. 1075-1083, 2020. 
[3] S. Jayasathyakawin, M. Ravichandran, N. Baskar, C. A. Chairman and R. Balasundaram, "Mechanical properties and applications of magnesium alloy-review," Materials Today: Proceedings, vol. 27, no. 2, pp. 909-913, 2020.

[4] A. Javadi, S. Pan and X. Li, "Scalable manufacturing of ultra-strong magnesium nanocomposites," Manufacturing Letters, vol. 16, pp. 23-26, 2018.

[5] Y. Ali, D. Qiu, B. Jiang, F. Pan and M. X. Zhang, "Current research progress in grain refinement of cast magnesium alloys: a review article," Journal of Alloys and Compounds, vol. 619, pp.639-651, 2015.

[6] L.Wang, E. Mostaed, X. Cao, G. Huang, A. Fabrizi, F. Bonollo, C. Chi and M. Vedani, "Effects of texture and grain size on mechanical properties of AZ80 magnesium alloys at lower temperatures," Materials \& Design, vol. 89, pp. 1-8,2016.

[7] M. Paramsothy, J. Chan, R. Kwok and M. Gupta, "Addition of CNTs to enhance tensile/compressive response of magnesium alloy ZK60A," Composites Part A: Applied Science and Manufacturing, vol. 42, pp. 180-188, 2011.

[8] Ş. Candan, S. Çim, S. Emir ve E. Candan, "AZ serisi Mg alaşımlarının korozyon davranışlarında B-Fazının rolü,"Düzce Üniversitesi Bilim ve Teknoloji Dergisi, c. 6, s. 4, ss. 1139$1162,2018$.

[9] Ö. Özgün, K. Aslantaş and A. Erçetin, "Powder metallurgy Mg-Sn alloys: production and characterization," Scientia Iranica, vol. 27, no. 3, pp. 1255-1265, 2020.

[10] A. Ercetin, Ö. Özgün and K. Aslantas, "Investigation of mechanical properties of Mg5Sn-xZn alloys produced through new method in powder metallurgy," Journal of Testing and Evaluation, vol. 49 , no. 5, pp. 3506-3518, 2021.

[11] A. Gökçe, "Toz metalurjisi yöntemiyle $\mathrm{Mg}$-Sn alaşımı üretimi ve karakterizasyonu," Akademik Platform Mühendislik ve Fen Bilimleri Dergisi, c. 8, s. 1, ss. 112-119, 2020.

[12] T. Aydoğmuş, F. Kelen ve E. Aydemir, "Sicak presleme yöntemi ile AZ91 Magnezyum alaşımının üretimi," Bitlis Eren Üniversitesi Fen Bilimleri Dergisi, c. 9, s. 1, ss. 277-287, 2020.

[13] L. Elen, Y. Türen ve E. Koç, "AZ91 Mg alaşımına farklı oranlarda Sbilavesi ile katılaşma hızının mikroyapı ve mekanik özelliklere etkisi," Uluslararası Mühendislik Araştırma ve Geliştirme Dergisi, c. 11, s. 2, ss. 451-463, 2019.

[14] T. Çetin, M. Akkaş ve M. Boz, "Gaz atomizasyonu yöntemi ile üretilen AM60 Magnezyum alaşım tozunun toz karakterizasyonu üzerine gaz basıncının etkisinin araştırılması," Gazi Üniversitesi Mühendislik Mimarlık Fakültesi Dergisi, c. 35, s. 2, ss. 967-977, 2020.

[15] A. H. Pahlevanpour, S. B. Behravesh, S. Adibnazari and H. Jahed, "Characterization of anisotropic behaviour of ZK60 extrusion under stress-control condition and notes on fatigue modelling," International Journal of Fatigue, vol. 127, pp. 101-109, 2019.

[16] D. H. Kang, S. S. Park and N. J. Kim, "Development of creep resistant die cast Mg-Sn-Al-Si alloy," Materials Science and Engineering A, vol.413-414, pp. 555-560, 2005.

[17] S. S. Park and B. S. You, "Low-temperature superplasticity of extruded Mg-Sn-Al-Zn alloy," Scripta Materialia, vol.65, pp. 202-205, 2011. 
[18] F. R. Elsayed, T. T. Sasaki, T. Ohkubo, H. Takahashi, S. W. Xu, S. Kamado and K. Hono, "Effect of extrusion conditions on microstructure and mechanical properties of microalloyed $\mathrm{Mg}$-SnAl-Zn alloys," Materials Science and Engineering A, vol. 588,pp. 318-328, 2013.

[19] A. Gökçe, "Magnezyum ve alaşımlarının toz metalurjisi işlemleri," Düzce Üniversitesi Bilim ve Teknoloji Dergisi, c. 8, s. 1, ss. 522-534, 2020.

[20] W. J. Li, K. K. Deng, X. Zhang, K. B. Nie and F. J. Xu, "Effect of ultra-slow extrusion speed on the microstructure and mechanical properties of $\mathrm{Mg}-4 \mathrm{Zn}-0.5 \mathrm{Ca}$ alloy," Materials Science and Engineering A, vol. 677, pp. 367-375, 2016.

[21] K. B. Nie, K. K. Deng, X. J. Wang, T. Wang and K. Wu, "Influence of SiCNanoparticlesaddition on the microstructural evolution and mechanical properties of AZ91 alloy during isothermal multidirectional forging," Materials Characterization, vol. 124, pp.14-24,2017.

[22] S. Q. Zhu and S. P. Ringer, "On the role of twinning and stacking faults on the crystal plasticity and grain refinement in magnesium alloys," Acta Materialia, vol. 144, pp. 365-375, 2018.

[23] K. K. Deng, J. Y. Shi, C. J. Wang, X. J. Wang, Y. W. Wu, K. B. Nie and K. Wu, "Microstructure and strengthening mechanism of bimodal size particle reinforced magnesium matrix composite," Composites Part A: Applied Science and Manufacturing, vol. 43, pp. 1280-1284, 2012.

[24] X. J. Wang, X. S. Hu, K. Wu, L. Y. Wang and Y. D. Huang, "Evolutions of microstructure and mechanical properties for Sicp/AZ91 composites with different particle contents during extrusion," Materials Science and Engineering A, vol. 636, pp. 138-147, 2015.

[25] K. K. Deng, X. J. Wang, M. Y. Zheng and K. Wu, "Dynamic recrystallization behavior during hot deformation and mechanical properties of $0.2 \mu \mathrm{m}$ SiCp reinforced $\mathrm{Mg}$ matrix composite," Materials Science and Engineering A, vol. 560, pp.824-830, 2013.

[26] K. Nie, Y. Guo, K. Deng and X. Kang, "High strength TiC/Mg-Zn-Ca Magnesium matrix nanocomposites with improved formability at low temperature,"Journal of Alloys and Compounds, vol. 792, pp. 267-278, 2019.

[27] H. Li, X. Dai, L. Zhao, B. Li, H. Wang, C. Liang and J. Fan, "Microstructure and properties of carbon nanotubes-reinforced magnesium matrix composites fabricated via novel in situ synthesis process," Journal of Alloys and Compounds, vol. 785, pp. 146-155, 2019.

[28] D. H. Cho, J. H. Nam, B. W. Lee, S. O.Yim and I. M. Park, "Thermal expansion properties of carbon nanotube/silicon carbide particle-reinforced magnesium composites fabricated by squeeze infiltration," Metals and Materials International, vol. 22, pp. 332-339, 2016.

[29] M. Habibnejad-Korayem, R. Mahmudi and W. J. Poole, "Work hardening behaviorof Mgbased nano-composites strengthened by $\mathrm{Al}_{2} \mathrm{O}_{3}$ Nano-Particles," Materials Science and Engineering A, vol. 567, pp. 89-94,2013.

[30] A. Erçetin, K. Aslantaş ve M. Perçin, "Toz metalurjisi yöntemiyle üretilen tungsten-bakır kompozit malzemelerin mikro frezelenmesi: kompozisyon ve sinterleme sıcaklığının etkisi,"Gazi Üniversitesi Mühendislik ve Mimarlık Fakültesi Dergisi, c. 33, s. 4, ss. 1369-1382, 2018.

[31] C. S. Goh, J. Wei, L. C. Lee and M. Gupta, "Development of novel carbon nanotube reinforced magnesium nanocomposites using the powder metallurgy technique," Nanotechnology, vol. 17, pp. 7-12, 2005. 
[32] C. D. Li, X. J. Wang, W. Q. Liu, H. L. Shi, C. Ding, X. S. Hu, M. Y. Zheng and K. Wu, "Effect of solidification on microstructures and mechanical properties of carbon nanotubes reinforced magnesium matrix composite," Materials \& Design, vol. 58, pp. 204-208, 2014.

[33] H. Mindivan, A. Efe, A. H. Kosatepe and E. S. Kayali, "Fabrication and characterization of carbon nanotube reinforced magnesium matrix composites," Applied Surface Science, vol. 318, pp. 234-243, 2014.

[34] A. Ercetin, Ö. Özgün, K.Aslantas and G. Aykutoğlu, "The microstructure, degradation behaviour and cytotoxicity effect of Mg-Sn-Zn alloys in vitro tests," SN Applied Sciences, vol. 2, no. 2, pp. 173, 2020.

[35] A. A. A. P. Silva, G. C. Coelho, C. A. Nunes, J. M. Fiorani, N. David and M. Vilasi, "Nb-Al binary system: reevaluation of the solubility limits of the $(\mathrm{Nb}), \mathrm{Nb}_{3} \mathrm{Al}, \mathrm{Nb}_{2} \mathrm{Al}$ and $\mathrm{NbAl}_{3}$ Phases at high temperatures," Materials Research, vol. 22, no. 5, pp. 1-8, 2019.

[36] M. Shanthi, P. Jayaramanavar, V. Vyas, D. V. S. Seenivasan and M. Gupta, "Effect of niobium particulate addition on the microstructure and mechanical properties of pure magnesium," Journal of Alloys and Compounds, vol. 513, pp. 202-207, 2012.

[37] M. Pul, "Zirkonya katkılı AZ91 magnezyum alaşımının mekanik davranışlarının incelenmesi," Mühendislik Bilimleri ve Araştırmaları Dergisi, c. 2, s. 2, ss. 30-37, 2020. 